\title{
Zinc Induced a Dramatic Enhancement of the Nonlinear Optical Properties of an Azo-Based Iminopyridine Ligand
}

\author{
Imen Guezguez, ${ }^{\ddagger \S}$ Awatef Ayadi, ${ }^{\ddagger}, \perp$ Karolina Ordon, ${ }^{\|}$Konstantinos Iliopoulos, ${ }^{\ddagger \dagger}$ Diana G. Branzea, \\ Anna Migalska-Zalas," Malgorzata Makowska-Janusik," Abdelkrim El-Ghayoury, \\ and Bouchta Sahraoui* ${ }^{*}$ \\ ${ }^{\ddagger}$ Laboratoire MOLTECH-Anjou, CNRS UMR 6200, Université d’Angers, 2 bd Lavoisier, 49045 Angers Cedex, France \\ ${ }^{\S}$ Laboratory Electronic and Microelectronic, University of Monastir, 5000 Monastir, Tunisia \\ ${ }^{\perp}$ Laboratoire de Physico-Chimie de l'État Solide, Université de Sfax, Route de Soukra, Km 4 BP 802, 3038, Sfax, Tunisia \\ "Institute of Physics, Jan Dlugosz University, Armii Krajowej 13/15, 42-200 Czestochowa, Poland \\ ${ }^{\dagger}$ Institute of Chemical Engineering Sciences, Foundation for Research and Technology Hellas (FORTH/ICE-HT), 26504 Patras, \\ Greece
}

\begin{abstract}
An azobenzene based iminopyridine ligand 1 has been synthesized by a condensation reaction between $\mathrm{N}, \mathrm{N}$ dimethyl-4,4' -azodianiline and 2 -formylpyridine. The complexation of the ligand with $\mathrm{ZnCl}_{2}$ afforded a tetrahedral neutral zinc metal complex (2) formulated as [(Azo-Imino-Py) $\left.\mathrm{ZnCl}_{2}\right]$. The crystal structure analysis of the complex indicates the formation of a tetracoordinated zinc(II) ion with the expected tetrahedral geometry. In solid state, a $2 \mathrm{D}$ supramolecular architecture reinforced by $\pi-\pi$ stacking and hydrogen bonding is observed. The UV-visible spectrophotometric titration studies of the ligand, by increasing amount of $\mathrm{ZnCl}_{2}$, confirm the existence of single complex species in solution. The nonlinear optical (NLO) investigations by Z-scan technique of both ligand $\mathbf{1}$ and complex 2 indicate a dramatic enhancement of the NLO absorption of the ligand upon complexation with $\mathrm{ZnCl}_{2}$. This enhancement is likely to be due to a large dipole moment found for the complex 2 as calculated by DFT/B3LYP methodology.

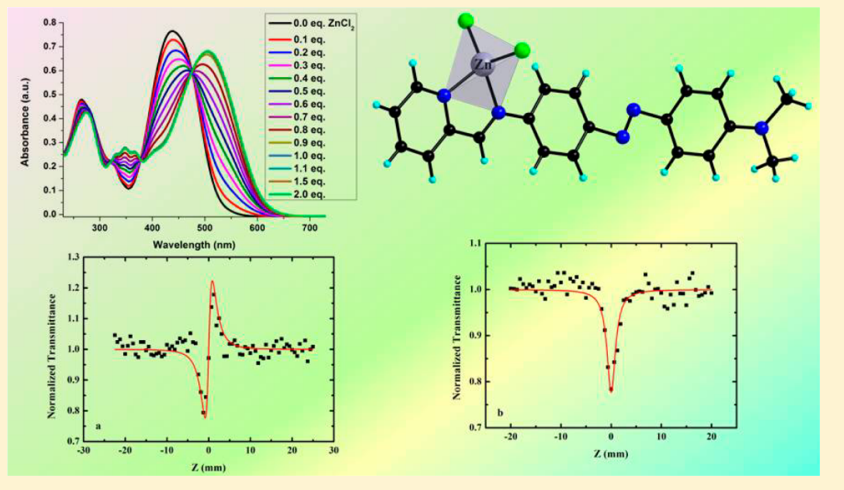

\section{INTRODUCTION}

Azobenzene $(\mathrm{AB})$ and its numerous derivatives are widely used in a large diversity of industrial applications. For instance, $A B$ based dyes are the most important group of synthetic colorants and represent $60-70 \%$ of the world production of "absorbing molecules". Moreover, $\mathrm{AB}$ is considered to be a molecular switch prototype possessing unique photochromic properties with stable cis and trans geometries related by two efficient and reversible photoisomerization processes. The photoisomerization occurs by UV irradiation concerning the $\pi-\pi^{*}$ absorption band changing trans to cis conformation. The reverse cis to trans isomerization takes place by blue light irradiation resulting in the $\mathrm{n}-\pi^{*}$ absorption band. ${ }^{2,3}$ Thus, the above-mentioned reversible isomerization needs two light sources and it is the basis for many functional materials with applications in nonlinear optics, ${ }^{4}$ optical storage media, ${ }^{5}$ chemosensors, ${ }^{6}$ optical switches, ${ }^{7}$ as well as a trigger protein folding. ${ }^{8}$ However, one of the ongoing challenges is the preparation of multifunctional molecular materials which can be created by the combination of two different molecular units bearing two different physical properties. These materials can therefore exhibit coexistence or synergy between two different physical properties. In order to address this challenge, considerable effort has been devoted to link covalently coordinating or binding unit to an $\mathrm{AB}$ photofunctional unit to produce photoactive metal complexes. For example, metal complexes of dithiolates, ${ }^{9}$ catecholates, ${ }^{10}$ bipyridines, ${ }^{7}$ terpyridines, ${ }^{11,12}$ Salens, ${ }^{13-15}$ and more recently diamine-based ligands have been synthesized. ${ }^{16}$ Pyridine based Schiff bases ligands such as 2-iminopyridyls with chelating abilities form stable complexes anchoring various transition metals. They have been used, for example, in metallo-organic self-assembling media to produce discrete metallo-supramolecular helicates, ${ }^{17-19}$ cages, ${ }^{20}$ and capsules. ${ }^{21}$ They have also been utilized with a variety of transition metals in catalysis. ${ }^{22,23}$

We have recently demonstrated the positive effect of the metal complexation on the nonlinear optical properties of some electroactive ligands. For example, we have reported an increase of the nonlinear optical behavior of orthogonal tetrathiafulvalene (TTF)-based ligands by the complexation with platinum as

Received: December 13, 2013

Revised: March 19, 2014

Published: March 21, 2014 
compared with palladium. ${ }^{24}$ In the case of TTF-based iron and ruthenium metal complexes we have observed switching of the nonlinear absorption character of the systems from Saturable Absorptive to Reverse Saturable Absorptive upon metal complexation. ${ }^{25}$ Moreover, we have recently shown an increase of the nonlinear optical response of TTF-based bisiminopyridine ligand coordinated with zinc cation. ${ }^{26}$ As the continuation of our research on the preparation of suitable materials for nonlinear optical applications, we report herein the synthesis, characterization, and nonlinear optical properties of an iminopyridine-appended azobenzene ligand and its corresponding neutral $\mathrm{Zn}$ (II) complex. It is worth noting that a dramatic increase of both the two photon absorption and the nonlinear refraction is observed in the case of the zinc complex as compared with the free ligand.

\section{EXPERIMENTAL METHODS}

Materials. Solvents for nonlinear optical measurements were of spectroscopic grade; all the other chemicals were of reagent grade quality and used as received.

Synthesis. $N, N$-Dimethyl-4-((E)-(pyridin-2ylmethylene) amino)phenyl) diazenyl) aniline (1). A solution of $\mathrm{N}, \mathrm{N}$ dimethyl-4,4'-azodianiline $0.500 \mathrm{~g}(2.08 \mathrm{mmol})$ and 2formylpyridine $0.222 \mathrm{~g}(2.08 \mathrm{mmol})$ in ethanol $(20 \mathrm{~mL})$ and few drops of acetic acid were heated under reflux overnight. After cooling to room temperature, the precipitate formed was filtered off and washed with ethanol. The desired product 1 was obtained as red powder in $80 \%$ yield.

${ }^{1} \mathrm{H}$ NMR (300 MHz, DMSO- $d_{6}$ ) $\delta / \mathrm{ppm}: 8.77$ (d, $1 \mathrm{H}, J=$ $4.71 \mathrm{~Hz}), 8.70(\mathrm{~s}, 1 \mathrm{H}), 8.21(\mathrm{~d}, 1 \mathrm{H}, J=7.88 \mathrm{~Hz}), 8.00(\mathrm{td}, 1 \mathrm{H}$, $J=7.69 .11 \mathrm{~Hz}, J=1.39 \mathrm{~Hz}), 7.88(\mathrm{~d}, 2 \mathrm{H}, J=8.67 \mathrm{~Hz}), 7.83(\mathrm{~d}$, $2 \mathrm{H}, J=9.11 \mathrm{~Hz}), 7.58(\mathrm{~m}, 1 \mathrm{H}), 7.52(\mathrm{~d}, 2 \mathrm{H}, J=8.62 \mathrm{~Hz}), 6.86$ $(\mathrm{d}, 2 \mathrm{H}, J=9.18 \mathrm{~Hz}), 3.09(\mathrm{~s}, 6 \mathrm{H}) .{ }^{13} \mathrm{C}$ NMR $(75 \mathrm{MHz}$, DMSO-d $\left.d_{6}\right) \delta / \mathrm{ppm}: 161.06,153.93,152.48,151.16,151.05$, $149.79,142.94,142.64,137.12,125.80,124.76,122.93,122.21$, $121.41,113.42,111.57,39.80$. Selected IR bands $\left(\mathrm{cm}^{-1}\right): \nu=$ 2896, 1596, 1515, 1360, 1132. MALDI-TOF MS calcd: $m / z=$ 329.16 Da. Found: $m / z=330.20[\mathrm{M}]^{+}$. HR-MS (M): for $\mathrm{C}_{20} \mathrm{H}_{19} \mathrm{~N}_{5}$ : 329.1640. Found 329.1649.

$N, N$-Dimethyl-4-((E)-(pyridin-2ylmethylene) amino)phenyl) diazenyl) aniline Zinc Chloride (2). In a test tube, a solution of ligand $110.01 \mathrm{mg}(0.03 \mathrm{mmol})$ in $\mathrm{CH}_{2} \mathrm{Cl}_{2}(5 \mathrm{~mL})$ was mixed with a solution of $\mathrm{ZnCl}_{2} 4.09 \mathrm{mg}(0.03 \mathrm{mmol})$ in $\mathrm{CH}_{3} \mathrm{CN}(5 \mathrm{~mL})$ and ultrasonicated for $2 \mathrm{~min}$. On top of the resulting solution a layer of diethyl ether was added, which led to the formation of single crystals of complex $\mathbf{2}$ after one week. Yield: (75\%).

${ }^{1} \mathrm{H}$ NMR (300 MHz, DMSO- $\left.d_{6}\right) \delta / \mathrm{ppm}: 8.82(\mathrm{~d}, 1 \mathrm{H}, J=$ $4.64 \mathrm{~Hz}), 8.75(\mathrm{~s}, 1 \mathrm{H}), 8.21(\mathrm{~d}, 1 \mathrm{H}, J=7.79 \mathrm{~Hz}), 8.07(\mathrm{t}, 1 \mathrm{H}, J$ $=7.46 \mathrm{~Hz}), 7.88(\mathrm{~d}, 2 \mathrm{H}, J=8.61 \mathrm{~Hz}), 7.83(\mathrm{~d}, 2 \mathrm{H}, J=9.15$ $\mathrm{Hz}), 7.64(\mathrm{t}, 1 \mathrm{H}, J=5.78 \mathrm{~Hz}), 7.54$ (d, $2 \mathrm{H}, J=8.58 \mathrm{~Hz}), 6.87$ $(\mathrm{d}, 2 \mathrm{H}, J=9.24 \mathrm{~Hz}), 3.09(\mathrm{~s}, 6 \mathrm{H}) .{ }^{13} \mathrm{C} \mathrm{NMR}(75 \mathrm{MHz}$, DMSO- $\left.d_{6}\right) \delta / \mathrm{ppm}: 193.75,160.73,152.54,152.31,151.25$, $151.15,150.26$, 149.79, 143.13, 142.95, 142.64, 137.70, 128.44, 124.80, 123.93, 123.41, 122.85, 122.47, 113.43, 111.69, 111.58, 39.92. Selected IR bands $\left(\mathrm{cm}^{-1}\right): \nu=1595,1557,1443,1361$. MALDI-TOF MS calcd: $m / z=428.06$ Da. Found: $m / z=$ 428.10. HR-MS (M): for $\mathrm{C}_{20} \mathrm{H}_{19} \mathrm{~N}_{5} \mathrm{ClZn}$ : 428.0620. Found 428.0614 .

Apparatus and Procedures. NMR spectra were recorded on a Bruker Avance DRX 300 spectrometer operating at 300 $\mathrm{MHz}$ for ${ }^{1} \mathrm{H}$ and $75 \mathrm{MHz}$ for ${ }^{13} \mathrm{C}$. Chemical shifts are expressed in parts per million (ppm) downfield from external TMS. The following abbreviations are used: s, singlet; d, doublet; $\mathrm{t}$, triplet; $\mathrm{td}$, triplet of doublet. UV-visible spectra were recorded at room temperature in quartz cuvettes using Perkin-Elmer spectrophotometer. Mass spectra were collected with Bruker Biflex-III TM. IR spectra were recorded on a Bruker vertex 70 .

Experimental X-ray diffraction data on single crystals were collected at room temperature using a Bruker Nonius Kappa CCD diffractometer operating with a Mo-K $\alpha(\lambda=0.71073 \AA)$ $\mathrm{X}$-ray tube with a graphite monochromator. The structures were solved (SHELXS-97) by direct methods and refined (SHELXL-97) by full-matrix least-squares procedures on $\mathrm{F}^{2}{ }^{27}$ All non-H atoms of the donor molecules were refined anisotropically, and hydrogen atoms were introduced at calculated positions (riding model), included in structure factor calculations, but not refined. X-ray diffraction measurements were performed on a Bruker Kappa CCD diffractometer, operating with a Mo $\mathrm{K} \alpha(\lambda=0.71073 \AA) \mathrm{X}$-ray tube with a graphite monochromator at a room temperature. Details about data collection and solution refinement are given in Table 1 . Crystallographic data for the structural analysis have been deposited with the Cambridge Crystallographic Data Centre, CCDC 974523 (complex 2).

Table 1. Crystal Data and Structure Refinement for 2

\begin{tabular}{|c|c|}
\hline compound & 2 \\
\hline empirical formula & $\mathrm{C}_{20} \mathrm{H}_{19} \mathrm{Cl}_{2} \mathrm{~N}_{5} \mathrm{Zn}$ \\
\hline fw & 465.67 \\
\hline$T(\mathrm{~K})$ & 293(2) \\
\hline wavelength $(\AA)$ & 0.71073 \\
\hline cryst syst & monoclinic \\
\hline space group & $P 21 / n$ \\
\hline$a(\AA)$ & $11.4347(7)$ \\
\hline$b(\AA)$ & $13.5824(6)$ \\
\hline$c(\AA)$ & $14.9356(7)$ \\
\hline$\alpha(\operatorname{deg})$ & 90 \\
\hline$\beta(\operatorname{deg})$ & $111.779(5)$ \\
\hline$\gamma(\operatorname{deg})$ & 90 \\
\hline$V\left(\AA^{3}\right)$ & $2154.08(19)$ \\
\hline$Z$ & 4 \\
\hline$D_{\mathrm{c}}\left(\mathrm{g} \mathrm{cm}^{-3}\right)$ & 1.436 \\
\hline abs coeff $\left(\mathrm{mm}^{-1}\right)$ & 1.403 \\
\hline$F(000)$ & 952 \\
\hline cryst size $\left(\mathrm{mm}^{3}\right)$ & $0.3 \times 0.2 \times 0.2$ \\
\hline$\theta$ range for data collection $(\mathrm{deg})$ & $2.10-27.51$ \\
\hline reflns collected & 4923 \\
\hline indep reflns & 2871 \\
\hline completeness (\%) & 99.3 \\
\hline refinement method & full-matrix least-squares on $F^{2}$ \\
\hline data/restraints/param & $4923 / 0 / 253$ \\
\hline GOF on $F^{2}$ & 1.047 \\
\hline final $R$ indices $[I>2 \sigma(I)]$ & $\mathrm{R} 1=0.0488, \mathrm{wR} 2=0.0981$ \\
\hline$R$ indices (all data) & $\mathrm{R} 1=0.1038, \mathrm{wR} 2=0.1230$ \\
\hline largest diff. peak and hole $\left(\mathrm{e} \AA^{-3}\right)$ & 0.332 and 0.370 \\
\hline
\end{tabular}

For the nonlinear optical measurements, the Z-scan technique has been utilized, employing a $\mathrm{Nd}: \mathrm{YVO}_{4}$ laser with a repetition rate of $10 \mathrm{~Hz}$ at $532 \mathrm{~nm}$. By means of the "open" and "divided" Z-scans the nonlinear absorption and the nonlinear refraction of the ligand and the complex have been separately determined. The $\mathrm{Z}$-scan technique is based on measuring the transmittance of the laser beam after the sample, while the latter moves along the transmission axis of a focused 
Scheme 1. Synthetic Scheme of Ligand 1 and Complex 2
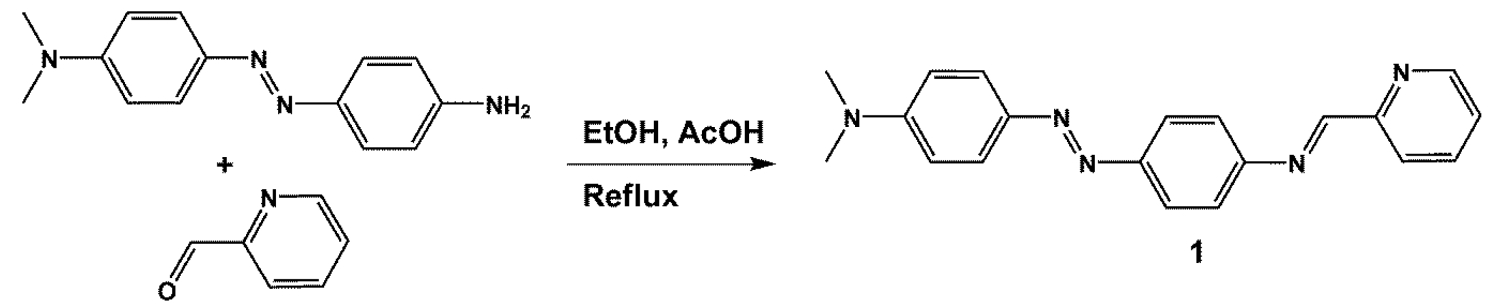

1

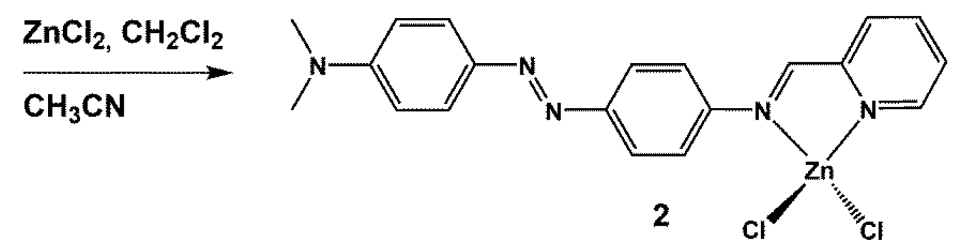

laser beam. During the "open" aperture Z-scan measurements the total transmission of the laser beam is detected. In order to obtain the "divided" Z-scan the so-called "closed" aperture Zscan is divided by the "open" aperture, while the former is obtained by measuring the transmittance of the laser beam after passing a narrow aperture. The advantage of the Z-scan technique is that it can provide both the sign and the magnitude of the nonlinear refraction and nonlinear absorption.

In particular, from the "divided" and "open" aperture Z-scans the nonlinear refractive parameter and the nonlinear absorption coefficient can be determined by mean of the following equations:

$$
\begin{aligned}
& T=\sum_{m=0}^{\infty} \frac{\left[-\beta I_{0} L_{e f f} /\left(1+z^{2} / z_{0}^{2}\right)\right]^{m}}{(m+1)^{3 / 2}} \\
& T=1-\frac{4 \Delta \Phi_{0} x}{\left(x^{2}+9\right)\left(x^{2}+1\right)}
\end{aligned}
$$

where $T$ is the normalized transmittance, $\beta$ is the nonlinear absorption coefficient, $L_{\text {eff }}$ is the effective thickness of the sample, $\Delta \Phi_{0}$ is the on-axis nonlinear phase shift at the focus, and it is related with the nonlinear refractive parameter through the equation

$$
\Delta \Phi_{0}=k I_{0} \gamma^{\prime} L_{\text {eff }}
$$

where $I_{0}$ is the on-axis intensity of the laser beam and $\gamma^{\prime}$ is the nonlinear refractive parameter. A dip or peak in the "open" aperture curves correspond to reverse saturable absorption (RSA) type behavior or saturable absorption (SA) type behavior, respectively. On the other hand the divided Z-scan curves can show a valley-peak or peak-valley configuration related to self-focusing or self-defocusing character of the investigated material, respectively. With the nonlinear absorption and nonlinear refractive parameters known, the real and imaginary parts of the third order nonlinear susceptibility can be determined according to the following equations:

$$
\begin{aligned}
& \operatorname{Re} \chi^{(3)}(\mathrm{esu})=\frac{10^{-6} \mathrm{cn}_{0}^{2}}{480 \pi^{2}} \gamma^{\prime}\left(\mathrm{cm}^{2} \mathrm{~W}^{-1}\right) \\
& \operatorname{Im} \chi^{(3)}(\mathrm{esu})=\frac{10^{-7} c^{2} n_{0}^{2}}{96 \pi^{2} \omega} \beta\left(\mathrm{cm} \mathrm{W}^{-1}\right)
\end{aligned}
$$

where $c$ is the speed of light in $\mathrm{cm} / \mathrm{s}$ and $\omega$ is the fundamental frequency given in cycles $\mathrm{s}^{-1}$. Finally the second order hyperpolarizability $\gamma$, which is an intensity-independent quantity, can be determined through the equation

$$
\gamma=\frac{\chi^{(3)}}{N L^{4}}
$$

where $N$ is the number of molecules per volume and $L$ is the local field correction factor.

Quantum Chemical Calculations. The structures of both investigated molecules $\mathbf{1}$ and $\mathbf{2}$ were modeled in vacuum using the $a b$ initio formalism implemented in GAMESS program package. $^{28,29}$ The initial geometries were built using ACD/ ChemSketch, an integrated software package from Advanced Chemistry Development, Inc. The minimum of the potential energy surface has been calculated at restricted Hartree-Fock (RHF) level ${ }^{30}$ with the standard $6-31 \mathrm{G}$ basis set in $C_{1}$ symmetry. The geometries of molecules were found applying the quadratic approximation (QA) optimization algorithm based on augmented Hessian techniques. ${ }^{31}$ The gradient convergence tolerance was equal to $10^{-4}$ Hartree/Bohr. At the end of geometry search the Hessian evaluation was performed to exclude the structures giving the negative modes and ensure the thermodynamic equilibrium of the molecule.

The modeled structures were used to compute the electronic properties of isolated ligand $\mathbf{1}$ and complex $\mathbf{2}$ performing quantum chemical calculations. The simulations were carried out applying the methodology of density functional theory (DFT) introduced in GAMESS program package. The time dependent DFT (TDDFT) calculations were performed using different exchange-correlation (XC) potentials in generalized gradient approximation (GGA), namely, the BLYP, B3LYP, and LC-BLYP. The B3LYP was finally chosen, as it has been found to be in very good agreement with the experimental findings. The hybrid B3LYP functional implemented in the GAMESS program package uses a linear combination of exact HartreeFock exchange as well as local and gradient-corrected exchange and correlation energies: ${ }^{32,33}$

$$
\begin{aligned}
E_{X C}^{\mathrm{B} 3 \mathrm{LYP}}= & 0.2 E_{X}^{\mathrm{HF}}+0.8 E_{X}^{\text {Slater }}+0.72 E_{X}^{\mathrm{B} 88}+0.81 E_{C}^{\mathrm{LYP}} \\
& +0.19 E_{C}^{\mathrm{VWN} 5}
\end{aligned}
$$

The single point calculations were performed with standard 6-31G basis set and with the one augmented by polarization and diffusion functions, $6-31++\mathrm{G}^{* *} .^{34-36}$ The RHF SCF energy convergence criterion was chosen to be $10^{-12}$ Hartree. 


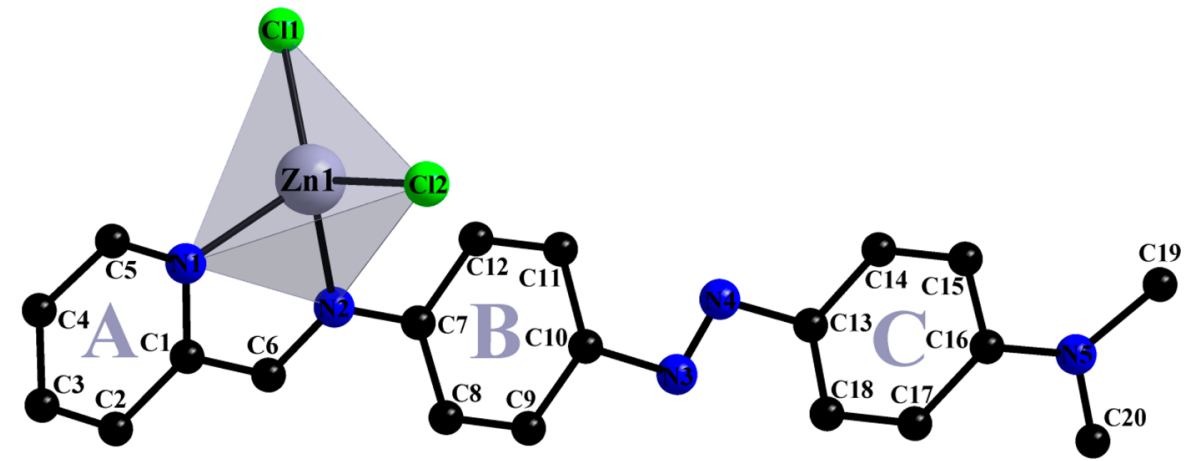

Figure 1. Crystal structure of Azo-Imino-PyZnCl ${ }_{2}$ complex.

Table 2. Selected Bond Lengths $(\AA)$ and Angles $\left({ }^{\circ}\right)$ in Complex 2 Measured Experimentally and Calculated Applying HF/6-31G Methodology

\begin{tabular}{|c|c|c|c|c|c|}
\hline \multicolumn{3}{|c|}{ bond length $(\AA)$} & \multicolumn{3}{|c|}{ angle values (deg) } \\
\hline & experimental data & $\mathrm{HF} / 6-31 \mathrm{G}$ obtained data & & experimental data & $\mathrm{HF} / 6-31 \mathrm{G}$ obtained data \\
\hline $\mathrm{N} 1-\mathrm{Zn} 1$ & $2.0570(3)$ & 2.11895 & $\mathrm{~N} 1-\mathrm{Zn} 1-\mathrm{N} 2$ & $81.04(12)$ & 78.723 \\
\hline $\mathrm{N} 2-\mathrm{Zn} 1$ & $2.0730(3)$ & 2.15390 & $\mathrm{~N} 1-\mathrm{Zn} 1-\mathrm{Cl} 1$ & $116.89(9)$ & 109.693 \\
\hline $\mathrm{Cl} 2-\mathrm{Zn} 1$ & $2.2129(12)$ & 2.29253 & $\mathrm{~N} 2-\mathrm{Zn} 1-\mathrm{Cl} 1$ & $120.71(9)$ & 110.124 \\
\hline $\mathrm{Cl} 1-\mathrm{Zn} 1$ & $2.1901(11)$ & 2.28450 & $\mathrm{~N} 1-\mathrm{Zn} 1-\mathrm{Cl} 2$ & $109.59(9)$ & 107.688 \\
\hline $\mathrm{C} 6-\mathrm{N} 2$ & $1.2630(4)$ & 1.26679 & $\mathrm{~N} 2-\mathrm{Zn} 1-\mathrm{Cl} 2$ & $106.80(8)$ & 112.388 \\
\hline $\mathrm{C} 7-\mathrm{N} 2$ & $1.4260(4)$ & 1.42205 & $\mathrm{Cl} 1-\mathrm{Zn} 1-\mathrm{Cl} 2$ & $116.45(5)$ & 127.427 \\
\hline
\end{tabular}

The UV-visible absorption spectra were calculated using the iterative Davidson method ${ }^{37}$ with an accuracy of $10^{-12}$ Hartree.

\section{RESULTS AND DISCUSSION}

Synthesis and Crystal Structure Description. Ligand 1 was prepared by a condensation reaction between $\mathrm{N}, \mathrm{N}$ dimethyl-4,4'-azodianiline and 2-formylpyridine in ethanol and a catalytic amount of acetic acid in $80 \%$ yield (Scheme 1). The reaction between the ligand $\mathbf{1}$ and the zinc chloride in a 1:1 ratio led to the formation of a monomeric complex 2 described here by the formula, $\left[\mathrm{ZnCl}_{2}(\mathbf{1})\right]$.

Suitable crystals for X-ray structural determination were grown by the slow diffusion of the mixture of the abovementioned reactants in $\mathrm{CH}_{3} \mathrm{CN}: \mathrm{CH}_{2} \mathrm{Cl}_{2}(1 / 1, \mathrm{v} / \mathrm{v})$ into an ethylic ether layer. Complex 2 crystallizes in the monoclinic space group $P 21 / n$ and its crystal structure is represented in Figure 1. The zinc ion is tetracoordinated with the expected tetrahedral geometry, the coordination sphere being formed by two chlorine atoms $(\mathrm{Cl} 1, \mathrm{Cl} 2)$ and two nitrogen atoms, one from the pyridyl ring (N1) and another iminic (N2) from the chelating Azo-Imino-Py ligand 1. The stereochemistry around the zinc ion is slightly distorted as evidenced by the differences between the values of the angles formed by the metal center with the donor atoms (see Table 2). This distortion is caused by the small bite size of the Azo-Imino-Py ligand 1, a common feature of imino-pyridyl type ligands, which results in a significantly narrow $\mathrm{N}-\mathrm{Zn}-\mathrm{N}$ angle $(\mathrm{N} 1-\mathrm{Zn} 1-\mathrm{N} 2$ $\left.81.04(12)^{\circ}\right)$ in comparison with the other angles around the zinc atom as well as the ideal tetrahedral angle. In the AzoImino- $\mathrm{PyZnCl}_{2}$ complex 2 the $\mathrm{Zn1-N1}$ (pyridyl) bond is somewhat shorter than the $\mathrm{Zn} 1-\mathrm{N} 2$ (imino) bond (both shorter than the $\mathrm{Zn}-\mathrm{Cl}$ bonds), and the length of 1.263(4) $\AA$ for the C6-N2 bond confirms no delocalization. The formal double bond character in the imino fragment is maintained (see Table 2).
The atomic bonds and angles in molecules $\mathbf{1}$ and $\mathbf{2}$ optimized by HF/6-31G methodology are presented in Table 2 . It is seen that the tendency of bonds is maintained. The tetracoordinated bonds of zinc ion have the same behavior as the experimentally measured ones. The computed bonds are overestimated by $3-$ $4 \%$ compared to the experimentally obtained data. In good agreement with the experimental data are lengths of $\mathrm{C} 6-\mathrm{N} 2$ and $\mathrm{C} 7-\mathrm{N} 2$ bonds. The bond $\mathrm{C} 6-\mathrm{N} 2$ is shorter than $\mathrm{C} 7-\mathrm{N} 2$ showing double bond behavior. Also, the $\mathrm{N} 1-\mathrm{Zn} 1-\mathrm{N} 2$ angle is very close to the experimental one. In addition, from the geometry optimization procedure it is seen that the $\mathrm{Zn}$ based tetrahedron is more flat than the experimental one as evidenced by the $\mathrm{Cl} 1-\mathrm{Zn}-\mathrm{Cl} 2$ angle, which is $11^{\circ}$ bigger for $\mathrm{HF}$ computations. We can conclude that the obtained geometry of isolated molecule is in good agreement with the experimentally predicted structural data.

In the crystal, each molecule of the complex interacts with two other neighboring molecules via hydrogen bonding established between the two chlorine atoms coordinated to the zinc ion and, respectively two hydrogen atoms, one belonging to a pyridyl ring ( $\mathrm{H} 5)$ and the hydrogen $(\mathrm{H} 6)$ of the

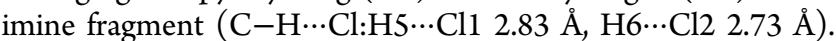
These interactions lead to the formation of $2 \mathrm{D}$ supramolecular layers parallel with the $b c$ crystallographic plane (Figure 2).

Within the layer, the molecules stack in parallel infinite columns with an offset head to head arrangement due to $\pi-\pi$ interactions involving, two by two, the aromatic rings from adjacent molecules (centroid $\cdots$ centroid: A $\cdots$ B $3.64 \AA$, B $\cdots \mathrm{C}$ $3.69 \AA$ ). Such a column is highlighted in red (Figure $2 \mathrm{a}$ ) and the supramolecular interactions between the neighboring molecules are represented in detail in Figure $2 b$.

UV-visible Spectroscopy. The electronic absorption spectrum of the ligand $\mathbf{1}$ was recorded in dichloromethane solution $\left(\sim 2 \times 10^{-5} \mathrm{M}\right.$ at room temperature; black line in Figure 3 ). This ligand exhibits two strong electronic absorption bands at $\lambda=266$ and $438 \mathrm{~nm}$ which are assigned to the $\pi \rightarrow \pi^{*}$ 


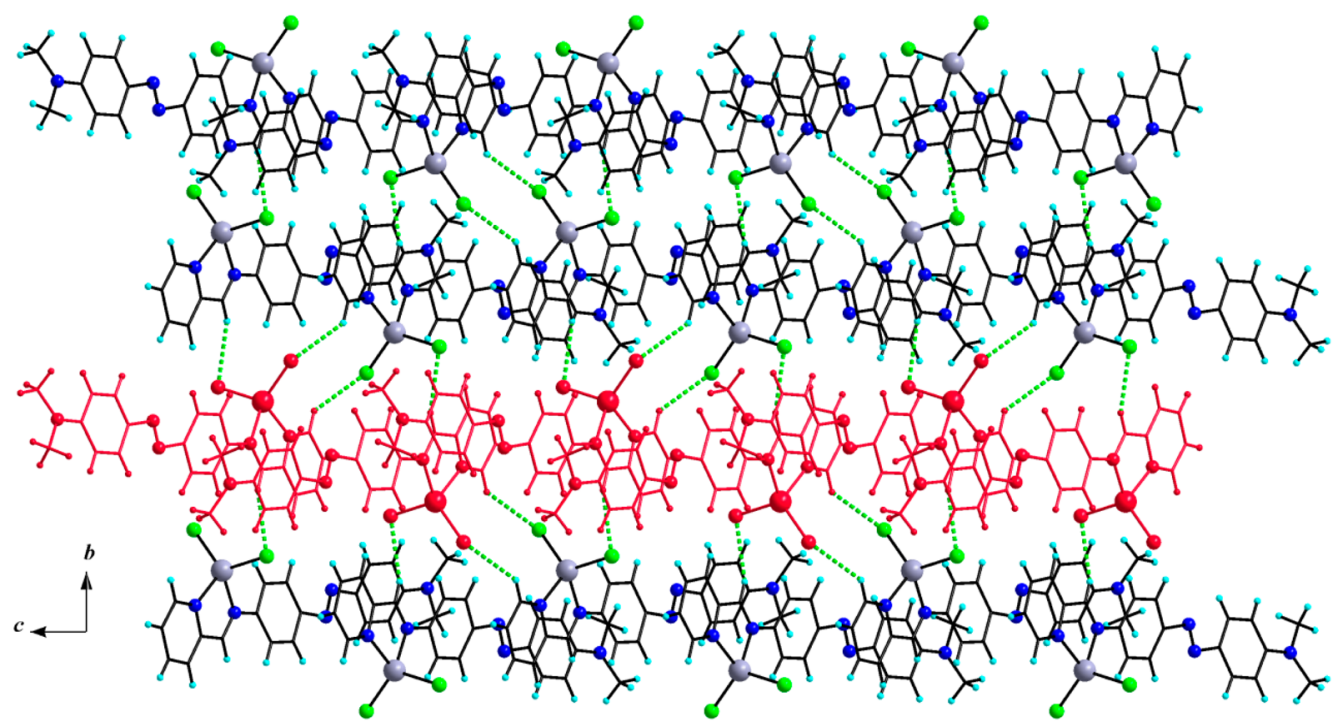

(a)

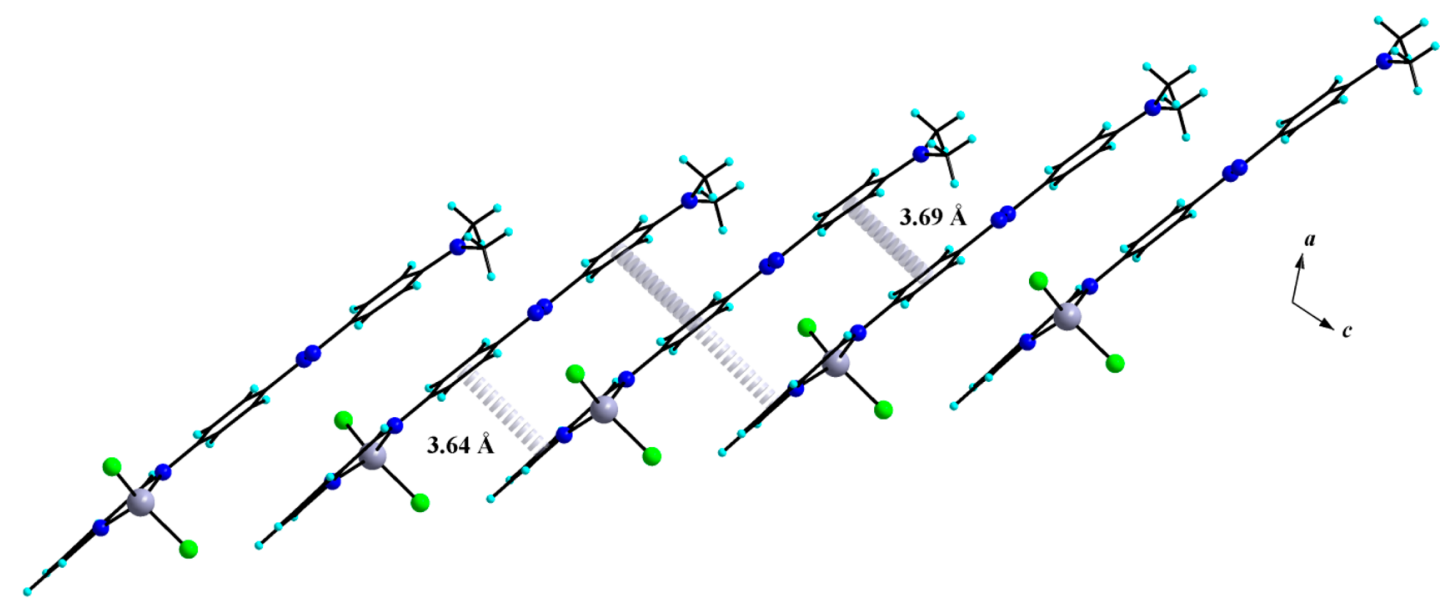

(b)

Figure 2. Perspective of the $2 \mathrm{D}$ supramolecular sheet generated by hydrogen bonding with an infinite column generated via $\pi-\pi$ stacking interactions between the aromatic rings of the ligands highlighted in red (a) and detailed in (b).

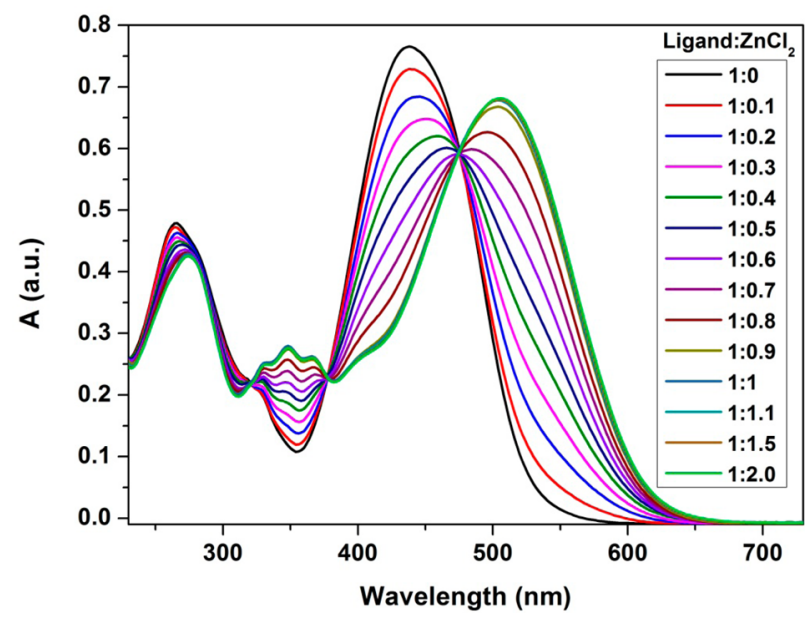

Figure 3. UV-vis titration of ligand $\mathbf{1}\left(\mathrm{C}=2.5 \times 10^{-5} \mathrm{M}\right)$ by $\mathrm{ZnCl}_{2}$ in a mixture of dichloromethane/acetonitrile, $1 / 1$.

and $n \rightarrow \pi^{*}$ absorption bands of the azobenzene moiety and the pyridyl ring together with a slight intramolecular charge transfer
(ICT) from the dimethylamino donor group to the iminopyridine accepting unit. ${ }^{26,38}$ In order to confirm the presence in solution of a single zinc complex specie, UV-visible electronic absorption titration was performed by adding increasing amounts of a zinc chloride into a $\mathrm{CH}_{2} \mathrm{Cl}_{2}$ solution of the ligand 1 (Figure 3). These additions result in a decrease of the band located at $266 \mathrm{~nm}$ and the appearance of the new band around $348 \mathrm{~nm}$ which corresponds to a ligand centered (LC, $\pi \rightarrow \pi^{*}$ and $\mathrm{n} \rightarrow \pi^{*}$ ) absorption and is probably due to conformational change of the ligand after complexation with zinc chloride. In addition, a significant bathochromic shift of the band in the visible region is observed. This shift is indicating an increase of the electron acceptor behavior of ligand $\mathbf{1}$ upon complexation with zinc chloride which acts as strong Lewis acid. The presence of three isosbestic points at 322,377 , and $475 \mathrm{~nm}$ clearly indicates the formation of single zinc complex species. Note that no additional absorption changes were observed upon introduction of more than 1 equiv of $\mathrm{ZnCl}_{2}$, as expected for the formation of 1:1 complex.

During the geometry structure optimization of ligand $\mathbf{1}$ by HF/6-31G method, two equivalent structures were obtained, namely, $\mathbf{1 a}$ and $\mathbf{1 b}$ (Figure 4). The total energy of $\mathbf{1 a}$ and $\mathbf{1 b}$ 


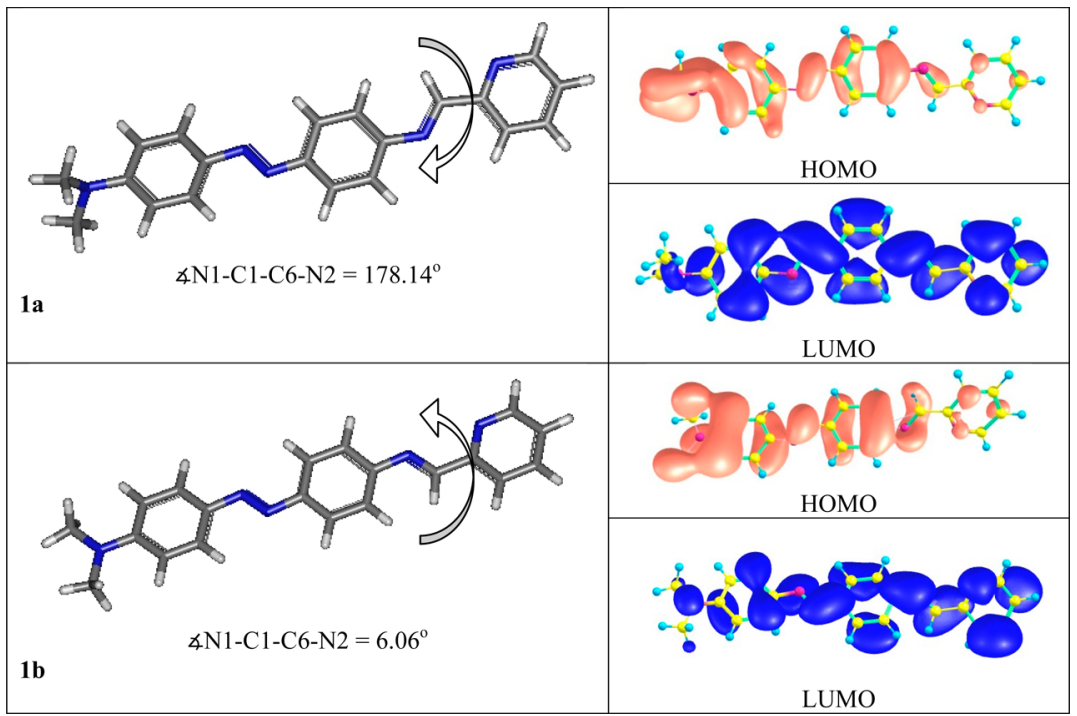

Figure 4. Two conformational structures of ligand $\mathbf{1}$ and the visualization of HOMO of $\mathbf{1 a}$ and LUMO of $\mathbf{1 b}$ conformations.

molecules is -1040.168 and -1040.172 hartree, respectively. These values suggest that the conformation $\mathbf{1 a}$ is more favorable although the environmental impact, like the presence of a light source or solvent molecules, may change the molecular conformation of the state $\mathbf{1} \mathbf{b}$. The variation of energy with the value of the torsional angle $\mathrm{N} 1-\mathrm{C} 1-\mathrm{C} 6-\mathrm{N} 2$ is shown in Figure 5. The represented data were calculated by molecular

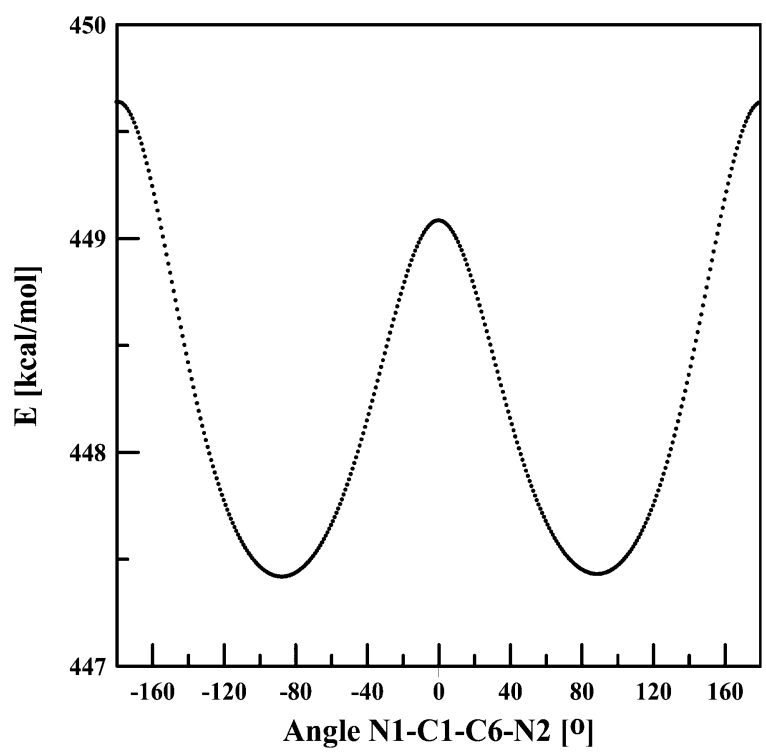

Figure 5. Energy of the torsional angle $\mathrm{N} 1-\mathrm{C} 1-\mathrm{C} 6-\mathrm{N} 2$ of ligand $\mathbf{1}$ computed by the molecular mechanics method using CVFF force field.

mechanics methodology using CVFF force field. The energies of the angle $\mathrm{N} 1-\mathrm{C} 1-\mathrm{C} 6-\mathrm{N} 2$ corresponding to the values of $6.06^{\circ}$ and $178.14^{\circ}$ are equal to 449.05 and $449.63 \mathrm{kcal} / \mathrm{mol}$, respectively. One may see that the torsional angle N1-C1$\mathrm{C} 6-\mathrm{N} 2$ present in conformations $\mathbf{1 a}$ and $\mathbf{1 b}$ has very similar energy. The potential barrier needed to overcome in the transition from conformation $\mathbf{1 a}$ to conformation $\mathbf{1 b}$ is equal to $1.82 \mathrm{kcal} / \mathrm{mol}$ (i.e., $0.08 \mathrm{eV}$ ), meaning that the two conformers may appear in the solvent used during the UV-visible absorption experiment (Figure 3).
Following the analysis of the structural results for ligand $\mathbf{1}$, the UV-visible absorption spectra were calculated for both conformers $\mathbf{1 a}$ and $\mathbf{1 b}$. The HOMO and LUMO orbitals for both conformers were computed and the results are represented in Figure 4. The HOMO orbitals for both conformations $\mathbf{1 a}$ and $\mathbf{1 b}$ are located on the dimetylamino group which has a donor character. The iminopyridine group plays the role of acceptor and the LUMO orbitals are predominantly located on its atoms. Comparing the HOMO and LUMO orbitals obtained for the conformers $\mathbf{1 a}$ and $\mathbf{1 b}$, one may say that the strongest charge transfer could occur for the electron transfer from HOMO of $\mathbf{1 a}$ to the LUMO of $\mathbf{1 b}$. This phenomenon may occur when molecule $\mathbf{1}$ changes configuration from $\mathbf{1 a}$ to $\mathbf{1 b}$ state during light absorption; conformational change is highly probable based on the calculated values of the energy corresponding to the N1$\mathrm{C} 1-\mathrm{C} 6-\mathrm{N} 2$ torsion angle mentioned above.

The calculated UV-visible absorption spectra for conformers $\mathbf{1 a}$ and $\mathbf{1 b}$ are shown in Figure 6. The two conformers present two absorption peaks, one at the position $440 \mathrm{~nm}$ and the second one around $365 \mathrm{~nm}$. When these spectra are compared with the experimental data (Figure 3), the first absorption peak fits very well (a small shift can be due to solvent effect). The peak at $440 \mathrm{~nm}$ is red-shifted as compared with the experimental data by about $100 \mathrm{~nm}$, and this significant change is probably due to some intermolecular interactions which are not taken into account in the performed computer simulations. By analysis of the spectra obtained for conformers $\mathbf{1 a}$ and $\mathbf{1 b}$ (Figure 6) the intensity of the first two absorption peaks shows a reverse character, suggesting also that a conformational change occurs during the UV-vis radiation.

Figure 6 clearly indicates the influence of metal complexation of ligand 1 by $\mathrm{ZnCl}_{2}$. In fact, with complexation, the UV-vis absorption spectra of the zinc complex suffer a bathochromic shift of the two main peaks for both theoretical and experimental data. The significant shift occurring in the visible region can be explained by an increase of the electron acceptor behavior of the ligand upon zinc complexation, also proven by the nature of the LUMO orbital in the zinc complex 2 (Figure 7). Furthermore, the appearance of an additional absorption shoulder is likely due to the conformational change (trans to 


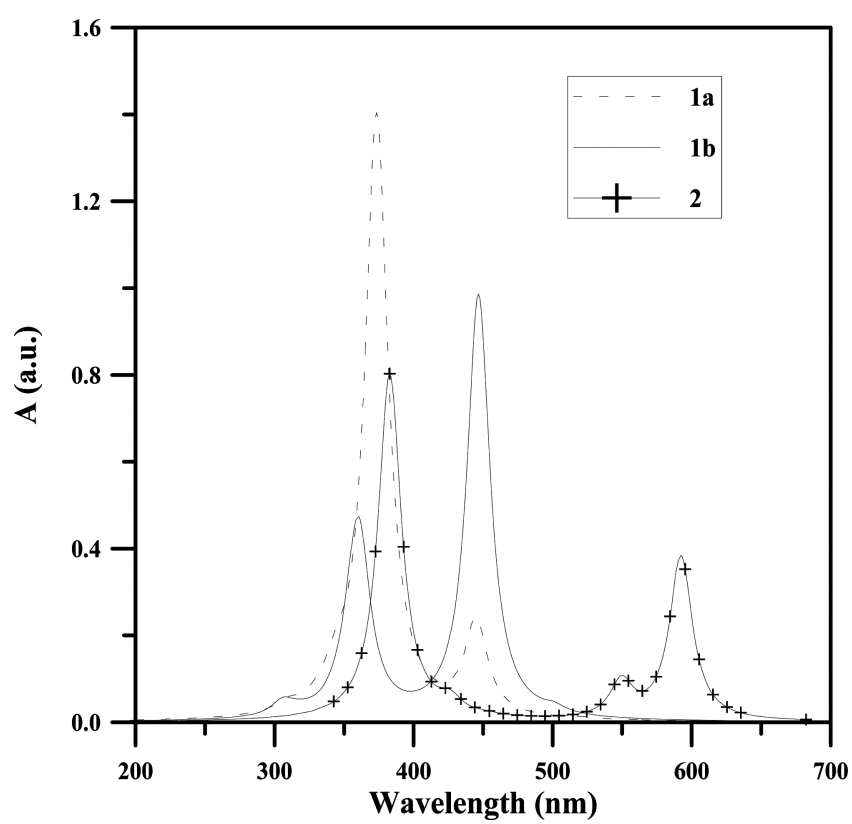

Figure 6. UV-visible absorption spectra computed by B3LYP/6-31+ $+\mathrm{G}^{* *}$ methodology.

cis) induced by the chelation of iminopyridine fragment to the zinc(II) ion.

Note that the complexation of ligand $\mathbf{1}$ with $\mathrm{ZnCl}_{2}$ drastically changes the polarity of the resulting metal complex 2 . Indeed, the calculated dipole moment of ligand 1a is equal to $1.08 \mathrm{D}$ while the dipole moment of $\mathbf{2}$ is $12.17 \mathrm{D}$. This clearly suggests that complex $\mathbf{2}$ is an appropriate candidate for NLO applications which can have a large response as compared with the free ligand.

Nonlinear Optical Properties. For the needs of the measurements several different concentrations of each sample have been prepared and put into 1-mm-thick cuvettes in order to be studied. The solvent (acetonitrile) has been separately measured and its contribution has been taken into account during the analysis of the experimental data. Different ranges of concentrations have been used in the case of ligand 1 and complex 2, which have been chosen by taking into account the magnitude of the nonlinearity as well as the linear absorption at the laser excitation wavelength $(532 \mathrm{~nm})$. In this sense the concentration in the case of ligand 1 has been varied between 1 and $2.5 \mathrm{mM}$, while in the case of complex 2 , which was found to have much stronger nonlinear optical response, significantly lower concentrations have been used $(0.01-0.1 \mathrm{mM})$. In this way, high signal-to-noise ratios were obtained in the case of the ligand, and the saturation limits for the nonlinearity were not reached in the case of the complex. In all cases, eq 5 was employed to determine the second order hyperpolarizabilities, taking into account the different concentrations that have been used. In Figure 8 are represented the characteristic divided and
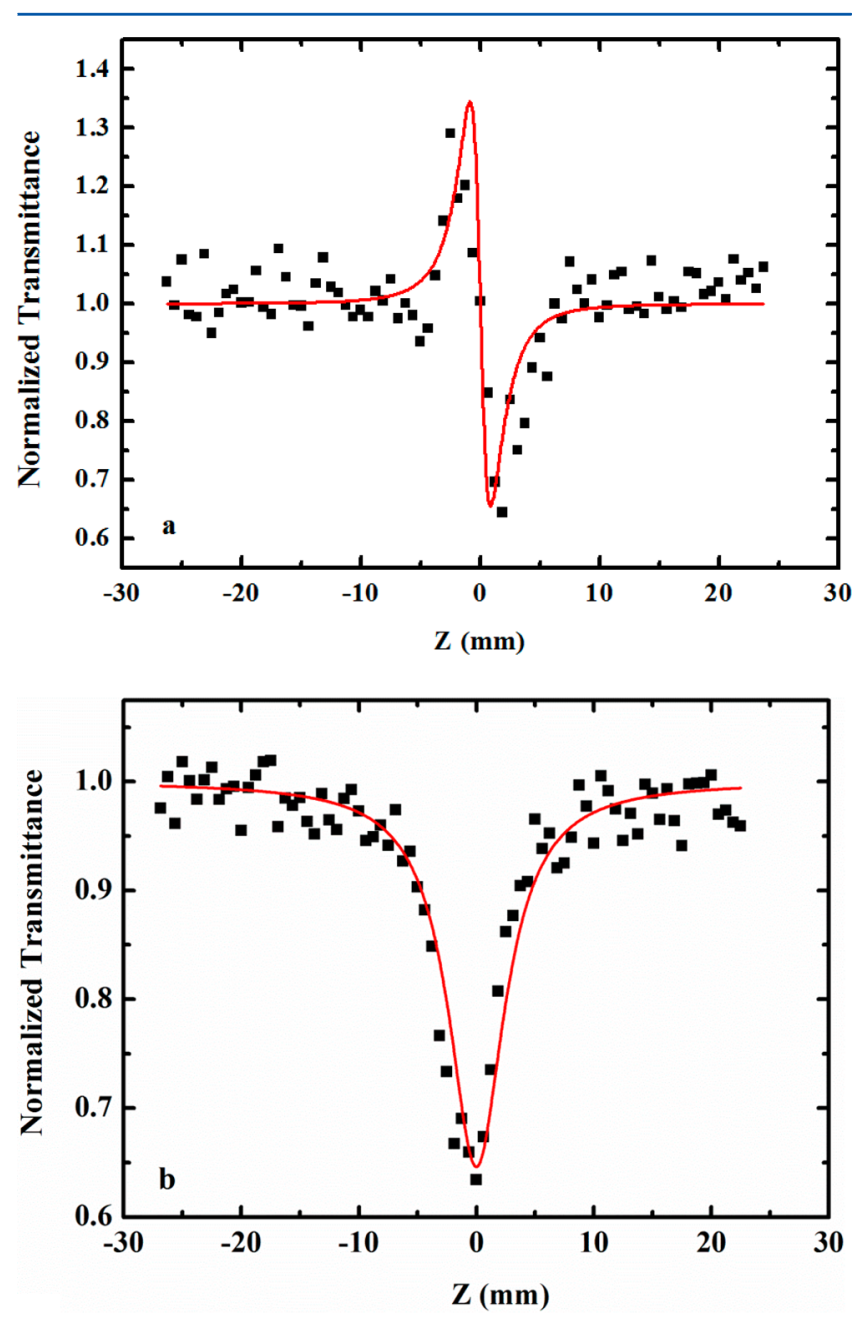

Figure 8. "Divided" (a) and "open" (b) aperture Z-scans corresponding to a $2.5 \mathrm{mM}$ concentration of the ligand in acetonitrile, both obtained at $E=0.8 \mu \mathrm{J}, \lambda=532 \mathrm{~nm}$.

open Z-scan curves, as well as the theoretical fits of the ligand (2.5 $\mathrm{mM}$ in acetonitrile). It is obvious that, in this case, the refraction is of self-defocusing character, as peak valley configuration (Figure 8a) has been found, while in the case of the nonlinear absorption, a dip corresponding to RSA-type behavior (Figure $8 \mathrm{~b}$ ) has been found. Both curves have been obtained for the same concentration and under the same experimental conditions. A dip in the "open" aperture curves has also been found in the case of complex 2 (see Figure 9a). On the contrary, concerning the nonlinear refraction of the zinc complex, a valley-peak has been found as can be seen in Figure

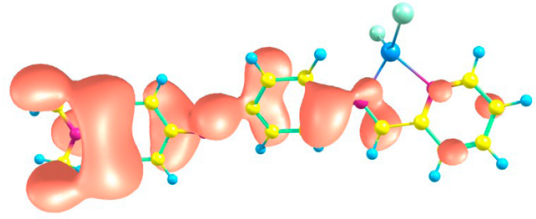

HOMO

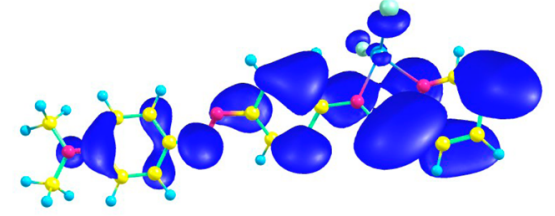

LUMO

Figure 7. Visualization of the HOMO and LUMO orbitals for complex 2 computed by HF/6-31++G** methodology. 

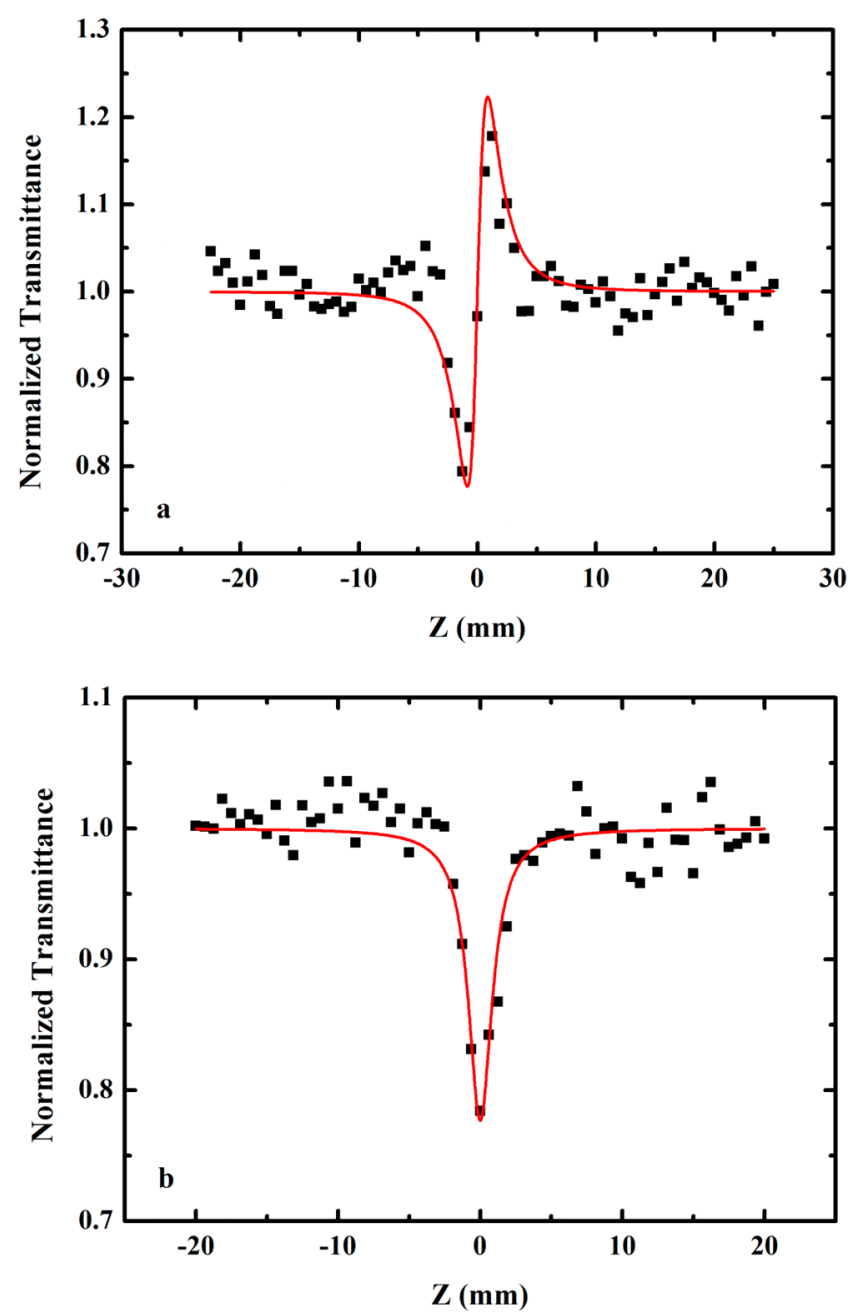

Figure 9. "Divided" (a) and "open" (b) aperture Z-scans corresponding to a $0.03 \mathrm{mM}$ concentration of the complex in acetonitrile $(E=1.7 \mu \mathrm{J}, \lambda=532 \mathrm{~nm})$.

9b. This clearly indicates that a change of the nonlinear refraction character from self-defocusing to self-focusing happens upon complexation of the ligand to the $\mathrm{Zn}$ (II) cation. Moreover, a dramatic increase of both nonlinear refraction and nonlinear absorption in the case of complex $\mathbf{2}$ has been observed with respect to those of the free ligand 1. As an example, we mention that the real and imaginary parts of the third order susceptibility corresponding to a $2.5 \mathrm{mM}$ concentration of the ligand in acetonitrile have been found to be $\operatorname{Re} \chi^{(3)}=-(8.73 \pm 1.5) \times 10^{-13}$ esu and $\operatorname{Im} \chi^{(3)}=(9.78 \pm$ 2.00) $\times 10^{-13}$ esu. These values have been obtained from several experimental curves corresponding to different laser energies (two characteristic curves have been presented in Figure 8). In the case of a $0.03 \mathrm{mM}$ solution of zinc complex 2, more precisely, a concentration more diluted with almost 2 orders of magnitude than that of the free ligand 1, the real and imaginary parts of the third order susceptibility have been determined to be $\operatorname{Re} \chi^{(3)}=(0.52 \pm 0.07) \times 10^{-13}$ esu and $\mathrm{Im}$ $\chi^{(3)}=(3.28 \pm 0.70) \times 10^{-13}$ esu.

Then, the second order hyperpolarizabilities have been determined according to eq 5 . In Table 3 we present the real and the imaginary parts of the second order hyperpolarizability. These values directly show different efficiency between the ligand and its complex. The real and imaginary parts of $\gamma$ show
Table 3. Nonlinear Optical Parameters of the Two Molecular Systems (532 nm, 30 ps)

\begin{tabular}{lccc} 
sample & $\operatorname{Im} \gamma\left(10^{-30} \mathrm{esu}\right)$ & $\operatorname{Re} \gamma\left(10^{-30} \mathrm{esu}\right)$ & $\gamma\left(10^{-30} \mathrm{esu}\right)$ \\
Ligand & $0.24 \pm 0.04$ & $-0.23 \pm 0.03$ & $0.33 \pm 0.05$ \\
Complex & $3.09 \pm 0.16$ & $1.20 \pm 0.40$ & $3.32 \pm 0.43$ \\
\hline
\end{tabular}

an increase of about 13 and 5 times, respectively, in the case of the zinc complex 2 compared with the free ligand, resulting in a significant enhancement of the total hyperpolarizability $\gamma$ of about 1 order of magnitude. This NLO response enhancement can be explained through the theoretical calculations performed. In fact, the dipole moment calculations indicate a much higher dipole moment for the zinc complex (12.17 D) as compared with the one of the free ligand $(1.08 \mathrm{D})$. In addition, the HOMO-LUMO frontier orbitals indicate a stronger donor-acceptor behavior in complex 2 , which is most likely caused by the Lewis acid character of $\mathrm{ZnCl}_{2}$ fragment.

\section{CONCLUSION}

During this work we have prepared a multifunctional ligand based on azobenzene as photoactive unit and the iminopyridine as a coordinating unit. The reaction of this ligand with 1 equiv of zinc chloride afforded the complex Azo-Imino$\mathrm{PyZnCl}_{2}$. The $\mathrm{X}$-ray structure of this complex indicates a tetrahedral geometry around the zinc atom and 2D supramolecular organization is observed in the crystal. The nonlinear absorption properties of the ligand as well as of the zinc complex have been investigated. A dramatic increase of both nonlinear refraction and nonlinear absorption in the case of complex $\mathbf{2}$ is observed in comparison with the free ligand $\mathbf{1}$. In fact, the real and imaginary parts of $\gamma$ show an increase of about 13 and 5 times, respectively, for complex 2 when compared with the free ligand, resulting in a significant enhancement of the total hyperpolarizability $\gamma$ of about 1 order of magnitude. This is likely due to a large dipole moment and stronger donor-acceptor behavior in the case of complex 2 as evidenced by $\mathrm{DFT} / \mathrm{B} 3 \mathrm{LYP}$ calculations. These results show that the covalent binding of an azobenzene moiety to a metal complex affords various useful characteristics such as modulation of the NLO response. In fact, the large variation of the NLO response upon metal complexation is an important phenomenon which opens new prospects for both photonic and opto-electronic applications.

\section{AUTHOR INFORMATION}

\section{Corresponding Authors}

*E-mail: abdelkrim.elghayoury@univ-angers.fr; Tel: +33 241 7354 92; Fax: +33241735405.

*E-mail: bouchta.sahraoui@univ-angers.fr; Tel: +332417354 89; Fax: +33241735405.

\section{Notes}

The authors declare no competing financial interest.

\section{ACKNOWLEDGMENTS}

Calculations have been carried out in Wroclaw Center for Networking and Supercomputing http://www.wcss.wroc.pl (Grant no. 171). K.I. acknowledges support from the European Commission and General Secretariat for Research and Technology (Greece) for a National Strategic Reference Framework (NSRF) Project (PE3-(1612)). The region Pays de la Loire is greatly acknowledged (Green SCO project). 


\section{REFERENCES}

(1) Zollinger, H. Color Chemistry, Syntheses, Properties and Applications of Organic Dyes and Pigments, 3rd ed.; Wiley-VCH: Weinheim, 2003.

(2) Tamai, N.; Miyasaka, H. Ultrafast Dynamics of Photochromic Systems. Chem. Rev. 2000, 100, 1875-1890.

(3) Schultz, T.; Quenneville, J.; Levine, B.; Toniolo, A.; Martìnez, T. J.; Lochbrunner, S.; Schmitt, M.; Shaffer, J. P.; Zgierski, M. Z.; Stolow, S. Mechanism and Dynamics of Azobenzene Photoisomerization. J. Am. Chem. Soc. 2003, 125, 8098-8099.

(4) Natansohn, A.; Rochon, P. Photoinduced Motions in AzoContaining Polymers. Chem. Rev. 2002, 102, 4139-4176.

(5) Muraoka, T.; Kinbara, K.; Kobayashi, Y.; Aida, T. Light Driven Open-Close Motion of Chiral Molecular Scissors. J. Am. Chem. Soc. 2003, 125, 5612-5613.

(6) Cheelham, A. G.; Hutchings, M. G.; Claridge, T. D. W.; Anderson, H. L. Enzymatic Synthesis and Photoswitchable Enzymatic Cleavage of a Peptide-Linked Rotaxane. Angew. Chem., Int. Ed. 2006, $45,1596-9$.

(7) Nashihara, H. Combination of Redox- and Photochemistry of Azo-Conjugated Metal Complexes. Coord. Chem. Rev. 2005, 249, $1468-1475$.

(8) Spörlein, S.; Carstens, H.; Satzger, H.; Renner, C.; Behrendt, R.; Moroder, L.; Tavan, T.; Zinth, W.; Wachtveitl, J. Ultrafast Spectroscopy Reveals Subnanosecond Peptide Conformational Dynamics and Validates Molecular Dynamics Simulation. Proc. Natl. Acad. Sci. U.S.A. 2002, 99, 7998-8002.

(9) Nihei, M.; Kurihara, M.; Mizutani, J.; Nishihara, H. Metalladithiolenes and Their Photo- and Proton-Responsive Isomerization Reactions. J. Am. Chem. Soc. 2003, 125, 2964-2973.

(10) Nagashima, S.; Nihei, M.; Yamada, T.; Murata, M.; Kurihara, M.; Nishihara, H. Synthesis of Azo-Conjugated Catecholate Complexes and their Photo- and Proton-Responses. Macromol. Symp. 2003, 204, 93-101.

(11) Yutaka, T.; Mori, I.; Kurihara, M.; Mizutani, J.; Kubo, K.; Furusho, S.; Matsumura, K.; Tamai, N.; Nishihara, H. Synthesis, Characterization, and Photochemical Properties of AzobenzeneConjugated $\mathrm{Ru}(\mathrm{II})$ and $\mathrm{Rh}(\mathrm{III})$ Bis(Terpyridine) Complexes. Inorg. Chem. 2001, 40, 4986-4995.

(12) Yutaka, T.; Mori, I.; Kurihara, M.; Tamai, N.; Nishihara, H. Photochemical Behavior of Azobenzene-Conjugated $\mathrm{Co}^{\mathrm{II}}, \mathrm{Co}^{\mathrm{III}}$, and $\mathrm{Fe}^{\mathrm{II}}$ Bis(terpyridine) Complexes. Inorg. Chem. 2003, 42, 6306-6313.

(13) Ye, Z.; De Boni, L.; Martins Neves, U.; Mendonça, C. R.; Bu, X. R. Synthesis and Two-Photon Absorption Property of Novel Salen Complexes Incorporated with Two Pendant Azo Dyes. Tetrahedron Lett. 2009, 50, 1371C1373.

(14) Khandar, A. A.; Nejati, K. Synthesis and Characterization of a Series of Copper(II) Complexes with Azo-linked Salicylaldimine Schiff Base Ligands. Crystal Structure of $\mathrm{Cu}_{5} \mathrm{PHAZOSALTNPCHCl}_{3}$. Polyhedron 2000, 19, 607-613.

(15) Dinçalp, H.; Toker, F.; Durucasu, I.; Avcıbasi, N.; Icli, S. New Thiophene-based Azo Ligands Containing Azo Methine Group in the Main Chain for the Determination of Copper(II) Ions. Dyes Pigm. 2007, 75, 11-24.

(16) Xia, X.; Huat Gan, L.; Huc, X. The Synthesis and Properties of Novel, Functional Azobenzene Based metal Complexes. Dyes Pigm. 2007, 75, 11-24.

(17) Ziessel, R.; Harriman, A.; El-ghayoury, A.; Douce, L.; Leize, E.; Nierengarten, H.; Van Dorsselaer, A. First Assembly of Copper(I) Naphthyridine-Based Helicates. New J. Chem. 2000, 24, 729-732.

(18) Young, M. C.; Johnson, A. M.; Gamboa, A. S.; Hooley, R. J. Achiral Endohedral Functionality Provides Stereochemical Control in $\mathrm{Fe}(\mathrm{II})$-Based Self-Assemblies. Chem. Commun. 2013, 49, 1627-1629.

(19) Howson, S. E.; Bolhuis, A.; Brabec, V.; Clarkson, G. J.; Malina, J.; Rodger, A.; Scott, P. Optically Pure, Water-stable, Metallo-Helical 'Flexicate' Assemblies with Antibiotic Activity. Nat. Chem. 2012, 4, $31-36$.
(20) Bolliger, J. L.; Belenguer, A. M.; Nitschke, J. R. Enantiopure Water-Soluble [Fe4L6] Cages: Host-Guest Chemistry and Catalytic Activity. Angew. Chem., Int. Ed. 2013, 52, 7958-7962.

(21) Bilbeisi, R. A.; Ronson, T. K.; Nitschke, J. R. A Self-Assembled [FeII12L12] Capsule with an Icosahedral Framework. Angew. Chem., Int. Ed. 2013, 52, 9027-9030.

(22) Cloete, J.; Mapolie, S. F. Functionalized Pyridinyl-Imine Complexes of Palladium as Catalyst Precursors for Ethylene Polymerization. J. Mol. Catal. A: Chem. 2006, 243, 221-225.

(23) Shejwalkar, P.; Rath, N. P.; Bauer, E. B. New Iron(II) $\alpha$ Iminopyridine Complexes and Their Catalytic Activity in the Oxidation of Activated Methylene Groups and Secondary Alcohols to Ketones. Dalton Trans. 2011, 40, 7617-7631.

(24) Iliopoulos, K.; Czaplicki, R.; El Ouazzani, H.; Balandier, J. Y.; Chas, M.; Goeb, S.; Sallé, M.; Gindre, D.; Sahraoui, B. Physical Origin of the Third Order Nonlinear Optical Response of Orthogonal Pyrrolo-Tetrathiafulvalene Derivatives. Appl. Phys. Lett. 2010, 97, 101104-101106.

(25) Iliopoulos, K.; El-Ghayoury, A.; El Ouazzani, H.; Pranaitis, M.; Belhadj, E.; Ripaud, E.; Mazari, M.; Sallé, M.; Gindre, D.; Sahraoui, B. Nonlinear Absorption Reversing Between an Electroactive Ligand and Its Metal Complexes. Opt. Express 2012, 20, 25311-25316.

(26) Iliopoulos, K.; Guezguez, I.; Kerasidou, A. P.; El-Ghayoury, A.; Branzea, D.; Nita, G.; Avarvari, N.; Belmabrouk, H.; Couris, S.; Sahraoui, B. Effect of Metal Cation Complexation on the Nonlinear Optical Response of an Electroactive Bisiminopyridine Ligand. Dyes Pigm. 2014, 101, 229-233.

(27) Sheldrick, G. M. Programs for the Refinement of Crystal Structures; University of Göttingen, Göttingen, Germany, 1996.

(28) Schmidt, M. W.; Baldrige, K. K.; Boatz, J. A.; Elbert, S. T.; Gordon, M. S.; Jensen, J. H.; Koseki, S.; Matsunaga, N.; Nguyen, K. A.; $\mathrm{Su}, \mathrm{S}$. J.; et al. General Atomic and Molecular Electronic Structure System. J. Comput. Chem. 1993, 14, 1347-1363.

(29) Gordon, M. S.; Schmidt, M. W. Advances in Electronic Structure Theory: GAMESS a Decade Later, in Theory and Applications of Computational Chemistry: the first forty years; Dykstra, C. E., Frenking, G., Kim, K. S., Scuseria, G. E., Eds.; Elsevier: Amsterdam, 2005; pp 1167-1189.

(30) Roothaan, C. C. J. New Developments in Molecular Orbital Theory. Rev. Mod. Phys. 1951, 23, 69-89.

(31) Jensen, F. Locating Transition Structures by Mode Following: A Comparison of Six Methods on the Ar8 Lennard-Jones Potential. J. Chem. Phys. 1995, 102, 6706-6718.

(32) Becke, A. D. Density-Functional Exchange-Energy Approximation with Correct Asymptotic Behavior. Phys. Rev. A 1988, 38, $3098-3100$

(33) Lee, C.; Yang, W.; Parr, R. G. Development of the Colle-Salvetti Correlation-Energy Formula into a Functional of the Electron Density. Phys. Rev. B 1988, 37, 785-789.

(34) Haharan, P. C.; Pople, J. A. The Influence of Polarization Functions on Molecular Orbital Hydrogenation Energies. Theor. Chim. Acta 1973, 28, 213-222.

(35) Frisch, M. J.; Pople, J. A.; Binkley, J. S. Self-Consistent Molecular Orbital Methods 25. Supplementary Functions for Gaussian Basis Sets. J. Chem. Phys. 1984, 80, 3265-3269.

(36) Clark, T.; Chandrasekhar, J.; Spitznagel, G. W.; Schleyer, P. Efficient Diffuse Function-Augmented Basis Sets for Anion Calculations. III. The 3-21+G Set for First-Row Elements, Li-F. J. Comput. Chem. 1983, 4, 294-301.

(37) Davidson, E. R. The Iterative Calculation of a Few of the Lowest Eigenvalues and Corresponding Eigenvectors of Large Real-Symmetric Matrices. J. Comput. Phys. 1975, 17, 87-94.

(38) Nita, G.; Branzea, D.; Pop, F.; El-Ghayoury, A.; Avarvari, N. Electroactive Bisiminopyridine Ligands: Synthesis and Complexation Studies. Crystals 2012, 2, 338-348. 